\title{
In the eye of the storm: Should I stay or should I go? Reflections on the middle phase of a problem-based learning group.
}

Keville, S., Nel, P.W, Jeffrey, S., Ford, D., Leggett, S., McCarney, R., \& Uprichard, S.

\begin{abstract}
This paper reports on the middle phase of a problem-based learning (PBL) group undergoing clinical psychology training at the University of Hertfordshire (UH). Trainers and trainees involved in PBL at UH provide some personal reflections on their experiences, highlighting some of the unique characteristics and dilemmas of participating in this middle phase of PBL. We explore themes around the dynamics within the group, the emotional experiences evoked for participants, and some of the strategies used to manage these emotions. We conclude with implications of this type of learning for clinical training.
\end{abstract}

\section{Introduction}

In 2006 we introduced problem-based learning (PBL) within the Doctorate in Clinical Psychology Programme curriculum at the UH. As part of reflecting on this experience, we published some of our views on starting off and ending this process together with one of our PBL training groups (Nel et al., 2008; Keville et al., 2009). Overall, PBL at UH currently comprises a formative exercise (small group presentation plus individual reflective essays), followed by four further summative exercises.

In this paper we provide some additional reflections, this time on the middle phase of the PBL journey, when, in 2007, exercises two and three were completed. These two exercises represented clinical examples that trainees may realistically encounter in their first year of training on their Adult Mental Health (AMH) and Older People (OP) clinical placements. Following the completion of the two small group presentations, every trainee was required to complete a 5000 word reflective essay, considering his or her own experience of participating in these two exercises.

\section{The PBL Exercises}


2. The AMH Exercise: This vignette focussed on a refugee who had contracted HIV via a drug induced rape. This was a multifaceted exercise, aimed at encouraging trainees to explore the complexity that can be involved in $\mathrm{AMH}$ cases, rather than focussing on 'text book' type cases with only one presenting problem.

3. The OP Exercise: This vignette was based on an older person with suspected memory loss. Presenting issues also involved the role of the family, bereavement, and trauma.

\section{Making space for the in-between}

As trainers and trainees we sometimes prefer to focus on the more positive learning aspects and outcomes of the training that we provide or undertake. However, within any part of clinical training there are likely to be phases of struggle that are more difficult to frame in such a positive way. ${ }^{1}$ It can also be difficult to acknowledge and talk about these experiences; to try and make sense of something that, at the time, might have scared us or that was experienced as difficult. In our experience, this may be particularly true within middle phases of the PBL process. In this phase one is neither at the beginning with hope, anticipation and excitement, nor at the end with some knowledge, resolution and relief.

In our previous paper on the final phase of PBL, one of the trainees hinted at some of these difficulties encountered in the middle phase:

I am starkly aware of the difficulty of change. It's nice to be in a precontemplative place where the status quo is comfortable. It's likewise nice to have come out the other end where you can reap the rewards of such changes.

The parts in between however can be frightening (Keville et al., 2009).

In our training, as in our clinical work, there is often a temptation to focus on beginning or end points. For example, assessment and evaluating outcome are often given a central role in lectures and in clinical practice. Yet what about the process that occurs in between the beginning and ending of training and therapy? Why may our focus here lessen, particularly if it shows more 'messiness' or more of a 'struggle'? Perhaps there

\footnotetext{
${ }^{1}$ In this paper we chose to foreground a part of clinical training that was perceived by those who participated in it as difficult and more of a struggle. However, we want to make it clear that we also appreciate the usefulness of focussing on the more positively experienced aspects of training. In line with Hornstrup \& Johansen (2009) we maintain that both approaches contain potential for learning.
} 
may be some value in bringing our attention to the in-between and sitting for a while with whatever may arise within us, both positive and negative? Can we remain in this unknown space for a while, connecting with whatever emotive response(s) that emerge? If we did, will it facilitate the decision making process of any difficult venture; that point when we have the option to remain or depart, to connect or disconnect with our experience?

The aim of this paper is to make space for reflecting on this in-between phase of the PBL process. To facilitate this, we once again include some reflections provided by the same group of trainees who participated in our two previous publications ( $\mathrm{Nel}$ et al., 2008; Keville et al., 2009). As before, each of the trainees were asked and agreed independently to participate in this, the third and final write-up of their PBL journey. They individually reviewed their own reflective essays relevant to the middle phase of PBL, drawing out a reflective summary that they felt comfortable to share with a wider audience. We followed this procedure mainly to ensure that the trainees had maximum control over how their experiences were given 'voice' in this paper. In addition to the trainee voices, the facilitator of the group (SK) also provided some of her own reflections on the process. It was important for us to make sure that as wide a range as possible of perspectives was accommodated in this final write-up. Moreover, although we strongly believe that this procedure enables us to provide a richer, more nuanced description of our numerous and complex sets of experiences, we also acknowledge that any account inevitably remains partial, incomplete and open to further elaboration and/or reinterpretation by any reader (including ourselves). We are aware that the reflections presented here can only ever be a small proportion of the many thoughts and feelings that we as participants (trainees and facilitator) had during or after the exercises.

\section{Reflections}

Although it was agreed to give contributors maximum control over how their voices were represented, we nevertheless took the collective decision to anonymise the accounts presented here due to the personal nature of some of the disclosures.

\section{Trainee 1}


PBL 2 had not been an exciting prospect for me both at an individual and group level. My perception was that there had been a number of unsaid, unresolved issues following the previous exercise. Reflecting on this, I did not doubt that as a group we would 'get the work done'; my anxiety related to the unknown element of how we would make it to the final presentation day.

PBL 2 began with a series of very difficult and emotional meetings both with and without our facilitator. Issues of conflict were raised and group members disclosed some feelings of marginalisation due to a belief they were 'unheard', whether they spoke or not, in our group meetings. At this point I was impressed and upset by some of the reflections being produced in the group, they were honest and unknown. This genuineness had quite an impact on me and I began to feel a deeper emotional connection with the group.

As we worked on PBL 3 I felt we became stuck once again. As a group we could work well at the content level, however when we shifted on to thinking about process there was almost a loud screeching noise, like the sound of an emergency stop on your driving test and the experience of flow disappeared. Our facilitator picked up on this and we were no longer able to hide from it, the 'unsaid' had returned and it was out in the open.

There were so many questions that I had. For example, why could we not remain congruent and genuine with each other? But I was also tired and frustrated about the thought of having to reflect on this in the group. It takes a lot of energy and emotional strength to be vulnerable and 'out there' (possibly this was the answer to my question above). This recognition developed my personal connection with our facilitator further. I have a lot of respect for her ability to raise the issues we find difficult to express. I feel this is a very difficult position to adopt in our group.

We were able to use our direct experience of the team not functioning, and the assumptions we make about individuals within teams, in our final presentation. In part this was via conscious effort but furthermore, I now recognise an unconscious drive for this focus, possibly as a method for communicating our own conflict, without having to name it. We placed it in the external environment which was maybe more comfortable and less damaging for the group. 
As a result of this I felt our group had been left without a resolution at the end of term. Our ending was unfinished and my anxiety began to develop in relation to the remaining two PBL exercises. It was almost akin to a series finale on TV where you are left with a cliff-hanger, except I had not been eager to engage in the next series, I just wanted to switch off.

\section{Trainee 2}

PBL 2 began with apprehension. The split in opinion from PBL1 regarding the degree to which we focussed on process issues within the group - and the rationale behind this - continued (Nel et al., 2008).

I feel that this split (content vs process) shaped our PBL experience at this stage. Process focussed meetings were experienced as uncomfortable and challenging. This would lead to us turning our attention back to the 'task', and in these discussions I noted feeling more like a group. By the end of PBL 2 we had developed an idea of what we liked and a shared sense of purpose. Our presentation went well and although things were not perfect, they were definitely moving in the right direction.

A debrief meeting with our facilitator shook our not so solid foundations. During the meeting our facilitator simply asked the questions that she usually did: Was there anything unspoken? How did we feel about the group process? Some members of the group - perhaps seen as the more talkative members - felt that we had begun to feel more cohesive as a group. However, this view was not shared by a minority, other members reported feeling unheard and overruled. Due to time limitations this meeting was never concluded and the issue was left unresolved.

The first meeting for PBL3 was offered as an opportunity to continue our last meeting. However, I felt that we spent little time thinking about this and instead turned our attention to the task. I remember feeling fearful of 'opening up a can of worms.' As PBL 3 continued the group felt cohesive and although there were disagreements, I felt comfortable discussing them. My experience was that although uncomfortable at times, the group was beginning to develop a working and communication style. About halfway through PBL3, during another facilitated meeting, we were again asked for our reflections. I was surprised that almost exactly the same thing happened. The more 
vocal members of the group began commenting on the cohesiveness of the group, and the same concerns were voiced by the quieter members. I noted feeling really frustrated at the end of this meeting, mainly because things had been going so well. Focusing on process issues had once again caused a rift in the group.

For me, a lot of what was driving the difficulties in our PBL experiences at this stage was the discomfort experienced in focussing on process related issues. I wonder if this led to us 'shutting down' during these meetings which led to us becoming stuck or 'destabilised.' For those more oriented to content-led work, spending so much time considering process-oriented issues might have been experienced as uncomfortable or unproductive. It was usually following these moments that the group would shift back to task-oriented activity and would 'progress.' Whilst process issues were difficult to discuss at this stage of PBL, I have learnt the value of recognising underlying processes that drive responses. I think that wanting to focus only on content could also be an experiential avoidance; ignoring the potentially uncomfortable emotional needs of the individuals in the group.

\section{Trainee 3}

Reflection in a work context was essentially a new endeavour for me. My work experience meant this was a faculty I had very little opportunity to develop prior to the course. This has changed considerably and I think a major contributor to the change was PBL.

A strong emotion I felt over the course of this particular phase of PBL was anger. This surfaced after a very emotive, facilitated group session. My initial fear of playing to a gender stereotype of 'acceptable' emotional responses was allayed when I realised that anger was something everyone in the group experienced. I was not quite sure what I was angry about and so the focus for this became the facilitation of the group. However, I did feel vulnerable expressing my anger as I did not think it fitted in with the emotional gamut I thought psychologists should have. However, this linked well to clinical work and understanding how the acceptance of negative emotional states is important by itself and can lead to change. Furthermore, not only can the emotional energy of anger be used in a positive way, it can also mask other emotions or issues, which cannot be addressed until the anger is acknowledged and worked through. 
Only when I accepted this anger, sat down with it and used it constructively, did I really begin to learn about the value of the reflective process. I realised that it gave me insight, allowed me to think about what was going on for me and what it was saying about me. Perhaps it was an inability to make sense of what was going on, or a reluctance to address certain issues, that fuelled this anger. It is possible that I was angry because my needs were not being met or that my input was not being appreciated by others in the group.

On reflection I now see that the facilitation enabled me - after periods of anger and confusion - to look within and to begin to look at our group working differently. This has involved acknowledging the complex interplay of individual, group and contextual dynamics that occurs in group interaction. While I have to admit that I do not fully understand activity at these levels and the interplay between them, and although I may never fully realise it, it is the challenge I take to future PBL exercises.

\section{Trainee 4}

I consider, from our group's interpretation of PBL experiences at this stage, that the concept of actually hearing the voices of our clients, as well as hearing the voices of our team, is of paramount importance to our ability to develop meaningful psychological formulations. In PBL 2, every effort was made within our group to reach out to actual individuals with similar experiences to the client (in the exercise). The benefit of doing this was that it enabled us to bring 'real' voices into our discussions, which helped to combat the feelings of detachment that our entire group commented on in our first exposure to the client's story. Initially, we had all found ourselves feeling like we were 'on autopilot' to some degree in our tendency to focus on developing a formulation of the client's difficulties. This perhaps mirrored actual clinical practice where, in multidisciplinary meetings, there is often a need to review a number of referral cases in a short space of time. However, there are clearly also significant disadvantages of avoiding the personal and individual distinctiveness that each individual case might bring.

In order to access some of the voices of those individuals with experiences similar to the client in the case, our group attempted to contact some of the supportive organisations and online forums involved with such clients. Our efforts were met with a rather mixed response. Many of our group experienced what might be described as an organisational 
block that appeared to be an effort to protect members from feeling they needed to share their stories with the outside world. A perceived need to protect the potentially vulnerable appeared to be a commendable endeavour, but in light of individuals often expressing concern that they did not know how to talk about their experiences outside of these forums, it was difficult to assess who was trying to protect whom.

It was perhaps at the point of us beginning to hear some of these voices that I found myself moving from a comfortably detached perspective, towards feeling overwhelmed by the stories as they tapped into my own personal experiences. Indeed, the group as a whole appeared to experience a similar 'block' through PBL 2. This might be best understood in Acceptance and Commitment Therapy terms whereby, through verbal or cognitive fusion, the word is able to invoke strong connections to the event itself (Hayes, Strosahl, \& Wilson, 2003). Indeed, as Hayes et al (2003) might argue, this shared language is the basis for understanding concepts we have not yet experienced. However, for me the personal connections were all the more vivid.

In terms of group working, my experience of the group through PBL 2 and 3, suggested that our group's ability to reflect on the difficult emotive content of the cases was a significant strength of the way we worked as a team. A primary reflection I have taken away from the personal and group experiences of these PBL tasks is a stronger belief in not being defined by the conditions that might bring a client to mental health services. Without hearing the voices of those we work with, clearly a difficult feat in consideration of the story bound characters of our vignettes, we inevitably run the risk of making snap judgements over those aspects of a case we might judge important.

\section{Trainee 5}

The process of writing my reflective essays for the second and third PBL exercises was a game of two halves. My first attempt was near finished two days before the deadline. It was one angry attempt, looking at groups and my PBL experiences from an individual point of view, with the take home message of a credulous and respectful approach to all, especially to me, and a critical reflection on training courses as nothing more than an exercise in knowing what is required and using the right 'buzz words' (Newnes, 2006). My proclamation of the stark differences between myself and others focused on the role 
of others to accept these differences, and I defiantly resisted accommodation or assimilation as I saw it, on my part. Fortunately this changed.

I switched tact with two days to the deadline and in contrast looked at groups and PBL from a group and more social psychology point of view. I discussed differences using Social Comparison Theory (Festinger, 1954). The focus here was more around how uncertainty leads people to assess their attitudes, abilities and emotions by comparing themselves with others in similar positions. This allowed me to expand this idea and reflect on how the uncertainty in the NHS can promote exaggerated divisions between different professional disciplines, and how mental health itself is a business built on the comparative concept of what is 'normal.'

I argued that the strong drive for cohesion and desire to experience a shared identity within our group meant normative pressures were strong (Asch, 1956; Festinger, 1954). I felt we were aligning our contributions rather than collecting them. Being somewhat divergent in my thinking at times, I began picking up tips in other contexts by watching psychologists I respected who tactfully identified themselves as playing 'devil's advocate' (Herbert \& Estes, 1977). Evaluation of them by others was not affected as they were playing a role rather than owning the viewpoint, unlike 'the group dissenter'. However, I was equally reassured in one such example that controversial opinions deviating from the dominant discourse, no matter how tactfully the point was made, can all too easily be fiercely and defensively shot down.

In PBL3, we questioned whether we had previously worked as a group, or merely collaborated. Subsequently, there was very little work that was undertaken independently. Working together meant each person could assume responsibility for any part, and the presentation was less fragmented. Gaining a sense of shared ownership also came with the disadvantages of lower motivation and less coordination (Steiner, 1972), combined with higher stress levels as a result of the conflict between attending to the task and to others, disagreements over details and regular misunderstandings, which seemed, at the time, to vastly outweigh the benefits.

\section{Facilitator (SK)}

My initial aim for this phase of PBL was to be in contact with what was occurring within the group at a verbal and non-verbal level, to connect with my own thoughts and 
emotions, and to share these with the group, where appropriate. Another aim became clearer as the group progressed into this middle phase of PBL: to facilitate ways in which all the different voices in the group could be allowed a space to speak, to be heard, and to be validated.

During one facilitated small group session, a trainee expressed a strong connection with some aspects of the client in the exercise's life story. The group approached a potentially emotive territory in their journey and, whilst they supported each other, I had a sense of disconnection with the exercise. It was as if, for this group, discussing their emotional reactions to the client's life story could potentially fracture an already fragile system: there was a tornado threatening to envelop them and they were seeking safety within its epicentre. At this point I made a conscious decision to keep reflective comments to a minimum. I suggested that we continue the discussion at our next meeting, but even after this meeting my sense of unresolved issues remained.

There was a brief acknowledgement of this at the beginning of the next exercise. When the group began to consider the clinical example, I was again impressed by their capacity for creative problem-solving. After 45 minutes of me sitting in silence, I recall reflecting internally on what I should do or say. There was no invitation for me to connect or disconnect with what the group was doing. I did not want to interfere with the group's creative flow, yet I also did not want to remain silent. As soon as I gave voice to my dilemma, the conversation became emotive. I soon realised that the experience of feeling silenced existed for others too. After a group discussion we agreed for the brainstorming to resume and for me to leave. At this point I was unaware that we had entered the eye of the storm again and that the tornado would continue in my next session with the group.

The next session opened with the trainees stating they had not met since the last facilitated meeting. Another group member felt responsible for the lack of group progress. It was an emotive response, one which took courage for this previously silent trainee to disclose. On the face of it the group were not focussing on the task in hand and were not structuring their PBL presentation; yet I think exploring this was pertinent and well within the realms of what PBL can be about - the task at this moment in time was on the group process. These issues were 'alive' and being acted upon in the here and now, but at times were remaining unspoken and unresolved. 
The next week, this PBL group produced a very good presentation. This group seemed to operate as one. There was a depth and quality to the work that seemed to be borne from a shared experience of this emotional journey. However, the journey was still not over. We were still fluctuating on the boundaries of the eye of the storm.

\section{Discussion}

In this section we consider two of the underlying themes connecting the above reflections and explore what we may learn from them for future exercises and groups.

\section{Emotional discomfort and emotional processing}

There can be a tendency in human nature to accept our emotional experience as the complete truth and, if distressed by our experience, to attempt to control it and/or to avoid it (Hayes et al., 2003). This can result either in suppressing our emotional responses or being reluctant to accept an alternative viewpoint. We can see in a number of the trainee accounts some of this being played out in the moment, and reflected upon later. However, being able to connect more openly with one's emotional responses, can help to challenge a fixed view, and thus provide greater flexibility both internally (intrapersonally) and externally (interpersonally).

The case material in the second exercise was particularly challenging on an emotional level for this group of trainees, and represented a significant hurdle for them to negotiate. This raises some interesting issues for those who construct PBL exercises on clinical courses like ours. For one, should we only present straight forward issues from areas unlikely to evoke distress; or should this type of learning reflect the realities of clinical work, or indeed, life itself? Many of us may, and will, have similar life experiences to the clients that we see. Therefore, perhaps it is best to be mindful of the potentially unsettling experience of working with these types of cases and the potential for learning through them.

Further, connecting with and reflecting on the process of the experience, whilst temporarily distressing, may facilitate a deeper learning that content focussed learning may not access (Bennett-Levy, 2006; Levine et al., 2006). In the moment, reflection may not have been a valued experience for some of these trainees. However, could this 
reluctance have been symbolic of an avoidance strategy? Whilst it may be an unspoken process, it does not mean that it does not exist. Resisting the urge to rescue trainees from these dilemmas and allowing them to connect with and express their struggle, or any negatively charged response to the process, can have far reaching positive implications. These implications may be apparent in the moment or further along in their training. For example, by allowing the trainees to see that they have the internal and external resources to access and utilise academic information to work with and manage cases; and self resilience in dealing with emotive responses to difficult issues. This may parallel processes involved in our clinical work.

Some trainees may continue to question aspects of the PBL experience. This can be a natural response if the challenges are perceived to be unmanageable or confusing. It can be helpful to validate this response, allowing trainees to experience any event in whatever way they do. Our three papers highlight how fluid and changeable our experiences and focus can be at any one time. This can be especially pertinent if we allow ourselves to process and digest the experience.

\section{Speaking out, silences and silencing}

The sense of speaking out, knowing how much to talk and, conversely, of feeling silenced was a strong theme in some of these accounts, and one that the facilitator had directly experienced too. Some trainees discussed this within the facilitated group meetings, whilst others chose to discuss it within their reflective accounts. This demonstrates the variety of responses to the same experience; the variety of methods used to deal with it; and the usefulness, or not, of reflecting on these methods (Levine et al., 2006).

For the facilitator this dynamic seemed to be a central theme at this stage of the PBL process, and one which seemed to drive much of what occurred within this group's dynamic. For learning to occur, her task was to show an active and overt interest in this: Why did only some group members speak? Why did others feel silenced? Why could some stories not be shared in the group? By making these inquiries in a respectful, tentative, and curious manner more can be learned about the unsaid.

Moreover, by providing the opportunity and space to identify, name and explore how the unsaid is responded to, individuals can be enabled to gain greater insight into their 
and others' role in any given interaction. Openness, acceptance and sincerity are integral parts needed to facilitate this process. The facilitator needs to create a context in which people are allowed space to reflect on their differences, to acknowledge their internal dilemmas (in whatever ways this may be expressed - whether it is by speaking out or not), and to feel genuinely appreciated for their own unique perspectives, experiences, differing viewpoints and histories. Perhaps there is a role for utilising strategies that may enable the individuals in the group to connect with this and each other. For example, Appreciative Inquiry (Hornstrup \& Johansen, 2009) might be one way to think about how one may assist trainees participating in PBL groups to name and validate what is useful in the experience and/or each other. Conversely, expressing the usefulness of dissent may encourage individuals to express their concerns rather than silently holding onto this, and potentially this being manifested via a lack of engagement in the group.

Finally, as a facilitator one must respect different trainees' ability and willingness to share their feelings in a PBL group. For learning to occur, it may not be necessary to discuss every issue and to disclose all of our historical baggage. What may be more fruitful, and respectful, is if we can openly discuss and accept our individual differences and comfort zones in relation to this. Further, learning to identify silences and having the courage to directly address them can help shift situations and/or interactions that may otherwise remain stuck, and which may freeze a system. Again, this can parallel similar processes involved in our clinical work, particularly those related to cancelled or unattended appointments.

\section{Conclusion}

For the trainees in this group the middle phase of their PBL journey was an unsettling one. They were faced with the dilemma: Should we stay, or should we go?

For us as trainers (SK and PN), the middle phase of this PBL journey seemed to highlight the importance of attending to the unsaid and the in-between; of connecting with one's own and others' experience, no matter how distressing it may be; of resisting the urge to troubleshoot and resolve distress simply because it exists; of staying with the here-and-now and only dealing with past issues as a means of contextualising them; of being honest and open and the facilitator modelling this for other group members (for 
example, using personal examples, in the hope that if you give more you may receive more); and of striving to find shared understandings.

At the end of their training we asked the same trainees for one final reflection on the process of PBL. They were asked what they had gained, if anything, from negotiating the intense middle phase of the PBL process. It is fitting, in our view, to conclude the paper with these reflections as illustration that PBL can facilitate a deeper learning that traditional didactic teaching may not so readily access.

\section{Sarah $J$.}

It is tricky to summarise my development through PBL in a few sentences. There are a range of things that I regularly apply to everyday situations, like resisting the urge to prematurely make decisions, to evade uncertainty, and seeking a credulous approach with others. But the most significant change has been being willing and better able to attempt to clarify or name what is going on, both in personal and professional relationships. This has helped me develop a deeper level of reflection, particularly over the last year. My experiences in PBL gave me the courage to talk frankly with clinical supervisors about process, first in relation to clients, and then within the supervisory relationship. Being able to talk about, and explore this level of relationships has helped challenge a lot of assumptions I held, and gain a closeness and openness in my personal relationships that I had not realised had been missing.

\section{Debbie}

After a few months respite from PBL I have to admit I began to miss it. It was not the exercises I missed, they had done their job already; equipping me with the confidence to tackle complex cases when they take you by surprise. I missed the closeness which has developed with most of my group members. I missed knowing I would see my group for some support if I was having a difficult week. I missed taking the obvious that one step further (an amazing skill I had learnt from our facilitator). Most of all I missed regularly witnessing the immense changes we had all made over the two PBL years. Although some personal changes appeared privileged over others in our group, I valued and will continue to value them all.

\section{Sarah L.}


In hindsight I've found PBL to be incredibly positive - particularly in job interviews and in team meetings. It has really set up a useful and creative way of thinking about groups and people. This has been noticed and commented on particularly at interviews. It has also made me braver about pushing to allow for safe reflective time in meetings and supervision as that was really at the core of what I found most beneficial in working in our group.

\section{$R o b$}

On an intensive course with so many other sources of learning and development it is difficult to pinpoint the precise contribution of PBL. My feeling is, however, that it provided me with a lot. There was an intensity about our sessions which made for an emotional, as well as intellectual, journey and while it was hard, I was grateful for it and know I have grown because of it. It is hard to summarise all of the things developed over this time but, for example, it was a great opportunity to really develop relationships with some members of my cohort. It was also useful learning how to continue working when there are difficulties within a team, and to gain and talk about other's perspectives on these difficulties. It helped make me a rounder individual and to begin to understand the part I play in a system.

\section{Steph}

PBL, like all valuable experiences, was something that will continue to influence me, personally and professionally throughout my career. My PBL experiences went far beyond developing my self-directed learning skills. During this sometimes difficult and painful journey, I began to develop my reflective and reflexive skills and had a chance to practice discussing process-related issues in a way that was containing, professional and productive. Being part of a PBL group that embraced the opportunity to take risks and even make mistakes, gave me the chance to learn about my own interpersonal style, and to be aware of, and take responsibility for, what I was bringing into my interactions with others. I feel that these experiences have all enriched my clinical work and I wonder when and how I would have developed these skills without PBL.

\section{References}

Asch, S. (1956). Studies of Independence and Conformity: A Minority of One Against a Unanimous Majority. Psychological Monographs, 70, (9, whole no. 416). 
Bennett-Levy, J. (2006). Therapist Skills: A Cognitive Model of their Acquisition and Refinement. Behavioural and Cognitive Psychotherapy, 34(1), 57-78.

Festinger, L. (1954). A Theory of Social Comparison processes. Human Relations, 7, 117-140.

Hayes, S.C., Strosahl, K.D., \& Wilson, K.G (2003). Acceptance and Commitment Therapy. An Experiential Approach to Behaviour Change. New York: Guilford Press.

Herbert, T. T. \& Estes, R. W. (1977). Improving Executive Decisions by Formalising Dissent : The Corporate Devil's Advocate. Academy of Management Review, 2, 662-667.

Hornstrup, C. \& Johansen, T. (2009). From Appreciative Inquiry to Inquiring Appreciatively. AI Practitioner, 11, 7-15.

Keville, S., Nel, P.W., Uprichard, S., McCarney, R.,Jeffrey, S., Ford, D., \& Leggett, S. (2009). Reaching the Journey's End: Reflections on the Final Phase of a Problem Based Learning Group. Reflective Practice, 10(5), 589-599.

Levine, R.B., Haidet, P., Kern, D.E., Beasley, B.W., Bensinger, L., Brady, D.W., Gress, T., Hughes, J., Marwaha, A., Nelson, J., \& Wright, S.M. (2006). Personal Growth During Internship. A Qualitative Analysis of Interns' Responses to Key Questions, Journal of General Internal Medicine, 21, 564569.

Nel, P.W, Keville, S., Ford, D., McCarney, R., Jeffrey, S., Adams, S., \& Uprichard, S. (2008). Close Encounters of the Uncertain Kind: Reflections on Doing ProblemBased Learning (PBL) for the First Time. Reflective Practice, 9(2), 197-206.

Newnes, C. (2006). Reflection and Power. Clinical Psychology Forum, 165, 36-39.

Steiner, I. D. (1972). Group Processes and Productivity. New York: Academic Press. 